\title{
Discussion on the Teaching of Internet Plus Public Service Course Based on PBL
}

\author{
Li Wang \\ School of Public Affairs and Administration \\ University of Electronic Science and Technology of China \\ Chengdu, China
}

\begin{abstract}
Aiming at the problems existing in the course teaching of Internet + public service, this paper puts forward the teaching method based on PBL, and further discusses the course implementation process, the specific method of course implementation and the guarantee measures for the implementation of PBL teaching method. This teaching method will help to cultivate students 'ability to think independently, innovate and collaborate, and further improve teaching results.
\end{abstract}

Keywords-PBL; Interne plus; teaching process

\section{INTRODUCTION}

On July 4, 2015, the Guiding Opinions of the State Council on Actively Promoting the "Internet + " Action was released, and the opinions clearly defined 11 key action areas of "Internet +": innovation and entrepreneurship, collaborative manufacturing, modern agriculture, smart energy, inclusive finance, beneficial services, efficient logistics, e-commerce, convenient transportation, green ecology, and artificial intelligence. Under the guidance of this policy, a number of colleges and universities have set up an "Internet + " compound training experimental class, aiming at cultivating students with solid "Internet + " core knowledge and innovation capabilities, that is, the data acquisition and processing technology based on intelligent information acquisition, sensor network, and big data application, the network technology with mobile Internet and information communication technology as the core, the security technology with information security as the core, and business management knowledge and ability with crowdsourcing and other business models as the core.

The Internet + Public Service course is a professional course in the direction of Internet +beneficial services. The goal of this course is to help students grasp the basic theory of public service, understand the trend of Internet + public service development, explore the path of Internet + public services which is suitable for Chinese actual situation, and ultimately have the focus of development in the field of analysis, and integrate Internet + technology to improve the quality of public service.

How to explain the Internet + Public Service course? There are still many uncertainties:

The first is the course itself. This course is a new course. There is no relevant experience to learn from. It requires teachers and students to have a sense of innovation. The technological frontier of Internet + also poses challenges for teachers and students, and for the maturity of Internet technology application, there are different voices. At the same time, the understanding of Internet thinking also affects the depth of the course.

The second is the students. The course is offered for the third-year undergraduate students. In the previous two years, the students belonged to the large-scale training. They have a good grasp of data analysis technology and corresponding computer programming techniques, but they do not involve knowledge in the field of public administration, public service theory and corresponding public service practices are almost blank. There is a strong expectation for the overall content structure of the course. Therefore, the logic requirements for the content of the course are relatively high, and more independent participation is required.

The third is the teaching mode. The traditional teaching mode mostly uses the cramming class explanation. The teacher masters the active knowledge transfer, ignoring the students' ability to participate independently. The whole process of teaching cannot improve enthusiasm of students, and cannot train communication and negotiation ability of students. Even if there are seminars, practice, and other forms of curriculum, teachers are the mainstay.

In view of this, in order to guarantee the teaching quality of the Internet + Public Service course, this paper intends to introduce the PBL teaching method to fully mobilize the enthusiasm of students.

\section{PBL TEACHING METHOD}

PBL is the first letter of Project Based Learning, also known as Problem-based or Product-based learning. PBL is a kind of teaching method driven by real tasks. The purpose of PBL is to enable students to mobilize their sense of autonomy and promote in-depth learning in the process of accomplishing meaningful tasks (mainly in the form of solving practical problems and making effective products).

PBL teaching method raises questions at the beginning of the course. Students learn with questions. When they become interested in solving these problems, they will become passive learning to actively participate and explore. Students have to go through the activities of questioning, judging, comparing, choosing and analyzing, synthesizing, generalizing for 
knowledge, and can obtain the solution of problems through various thinking and cognitive methods. In fact, students gradually acquire the ability to comprehensively think and solve problems[1][2].

PBL focuses on developing three abilities of students: critical thinking, collaboration, and communication. The teaching mode is fundamentally different from the traditional teaching mode in terms of design concept, implementation method, evaluation system and actual effect.

The following points should be paid attention to in the teaching of Internet + public service course based on PBL[3][4] :

\section{Students as the main body}

\section{Focus on problem design}

3. Reform the traditional evaluation system.

4. The implementation links should be based on the three abilities of the students.

III. The content of the Internet + Public Service course based on PBL

\section{A. Principles for setting course content}

PBL teaching is based on problems and highlights the main position of students in teaching. Therefore, how to design a problem system suitable for students to participate in chapters is of great importance. The design principles of the problem system are as follows:

\section{a. Students are the main body}

The design of the problem system cannot be handled by the teacher. It should take the students as the main body, fully mobilize the enthusiasm of students. The teacher puts forward a big framework of the course content, and the students are responsible for the specific problem design.

\section{b. Systematic principles}

The design of the problem system follows the overall logic of "why? What? How?". Proceed from the whole situation, decomposes a large project task into a small sub-project task, on the basis of which, designing the corresponding problem from different angles.

\section{c. Moderate difficulty}

Because students have different levels of foundation, the difficulty of problem design should be moderate and meet the needs of students at different levels.

\section{B. Course content setting}

From the beginning of the title of the course, Internet + Public Service contains three conceptual systems, namely the in-depth integration of Internet + technology, public services, and Internet + public services. As shown in "Fig. 1".

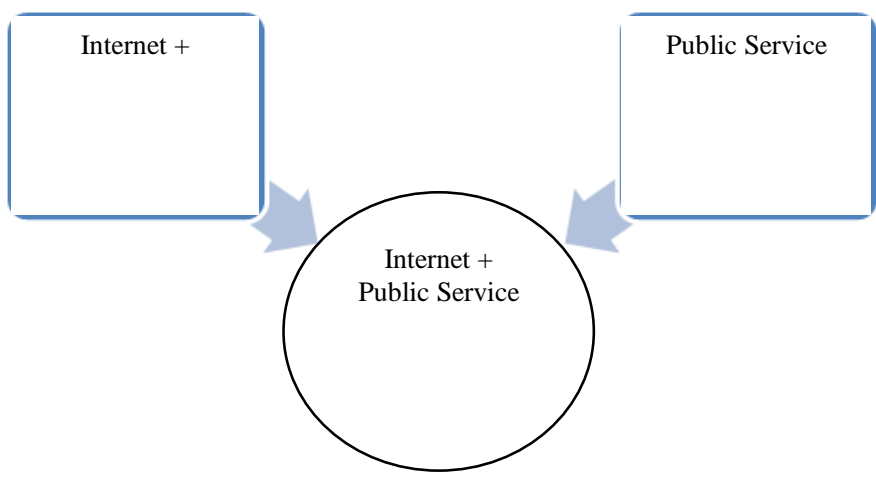

Fig. 1. Concept system.

Guide students to consult relevant literature and answer the following questions:

(1) Internet +

A. Background of Internet + ?

B. What is Internet + ?

C. Deployment of national Internet + ?

D. The application of Internet + in other industries?

(2) Public service

A. What is public service?

B. Classification of public services?

C. What are the main bodies of public service provision? What is the difference?

(3) Internet + public service

A. Internet + public service add what?

B. Internet + public service how to add?

This course focuses on the Internet + public services. Due to limited class hours, the medical and health fields are selected in public services. The course intends to find out the pain points in the traditional field based on a comprehensive study of the current situation in the field of medical health. Analyze the current situation and future development direction of Chinese Internet + medical health industry, and consider how to make full use of Internet technology to improve public service quality.

Take Internet + medical health as an example. According to the logic of "Why? What? How?", step by step, focus the research topics on:"Why discuss Internet + medical health? What is Internet + medical health? How to determine the research angle of Internet + medical health?" and so on. In this way, students are guided to design the overall framework of the course content together and give corresponding class time arrangements. As shown in "Fig. 2". 
Course content framework:

Collect relevant research literature, conduct bibliometric analysis, and obtain the hot spot of Internet + medical health research -- Scholars Perspective (2 class hours)
Screening domestic key enterprises and typical platforms for case analysis, summing up experience, predicting development trends -Classic Case (6 class hours)
Summarize Internet + medical health construction mode, service mode, operation mode and profit mode -- Operation Practice (8 class hours)

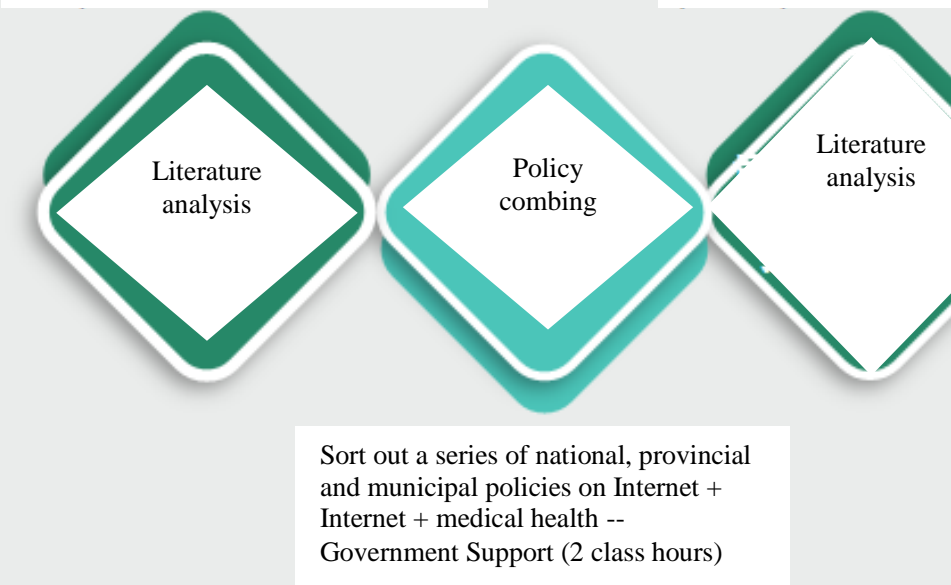

layout of international technology giants, mobile phone giants, BAT, and some listed companies on the Internet + medical health -- Corporate Vision (6 class hours)

Fig. 2. Internet + medical health content system .

\section{IMPLEMENTATION OF INTERNET Plus PUbliC SERVICE COURSE BASED ON PBL}

\section{A. Implementation Process}

Take Internet + medical health as an example. The basic implementation process is as follows:

- Respect students in the classroom, teachers and students negotiate together to draw up a course content framework (large tasks are broken down into small modules).

- Give the completion goals of each module and assign the appropriate class hours to each module.

- Students design open questions for each module, question-oriented, and obtain answers and solutions through multiple channels.

- In the classroom, under the guidance of the teacher, discuss the problems found in the course design and in the study. Students use the knowledge they have learned and the information collected to participate in the discussion. The disagreement can be debated. Teachers are invited to explain the bigger disagreement. After the discussion, each group will present the results of the group discussion and the issues that are divided. The teacher summarizes the results of the student discussion and summed up the knowledge system. The teacher pays attention to the problems that students have major differences. The questions that students still do not understand are left to the students to discuss and solve after class, but they should give relevant tips and guidance.

In the whole process, students are the main body of learning, teachers and students are equal in status, and students actively participate. Around each small module, they ask questions, analyze problems and solve problems, and finally discuss the results with everyone and record the conclusions. It can be seen that students can fully exert their subjective initiative and exercised the autonomous learning ability of students. As the core of the traditional teaching model, teachers fully play a guiding role in the PBL teaching process, guiding students to create a framework for teaching content, break down the content framework, create a problem system for each module, and support the interaction between group members, explain the most divergent issues and key theories of students.

\section{B. Implementation Mode}

According to the depth of the problem and the participation of students, the following teaching implementation modes can be freely switched in the classroom. As shown in Figure 3.

1) Organizing groups: According to the class size, student willingness, student ability and other indicators, students are divided into several groups. Throughout the semester, teaching activities are conducted in groups and team leaders are designated.

2) Harkness (Harkness round table): This approach was a discussion-style classroom model demanded by American oil 
tycoon Edward Harkness when he donated to Exeter in the 1930s. At present, many elite schools and private universities in Europe and America are keen on this kind of round table discussion teaching method, which allows students and teachers to communicate directly and even discuss with each other. And fully activate the initiative of teachers and students with high-level participation and open progress. This form of constructivism is popular among many college students.

3) Put questions: For inactive students, teachers can ask questions appropriately, attract attention of students in class, and promote students to prepare actively before class.
4) Traditional explanation: The traditional way of teachers explanation can be adopted for the content that involves key theories and has great differences among students.

5) Student report: For some modules of the problem system, the classroom can be completely handed over to the students to explain, the students dominate the classroom, explain their report content, organize discussion and finally record classroom reflection.

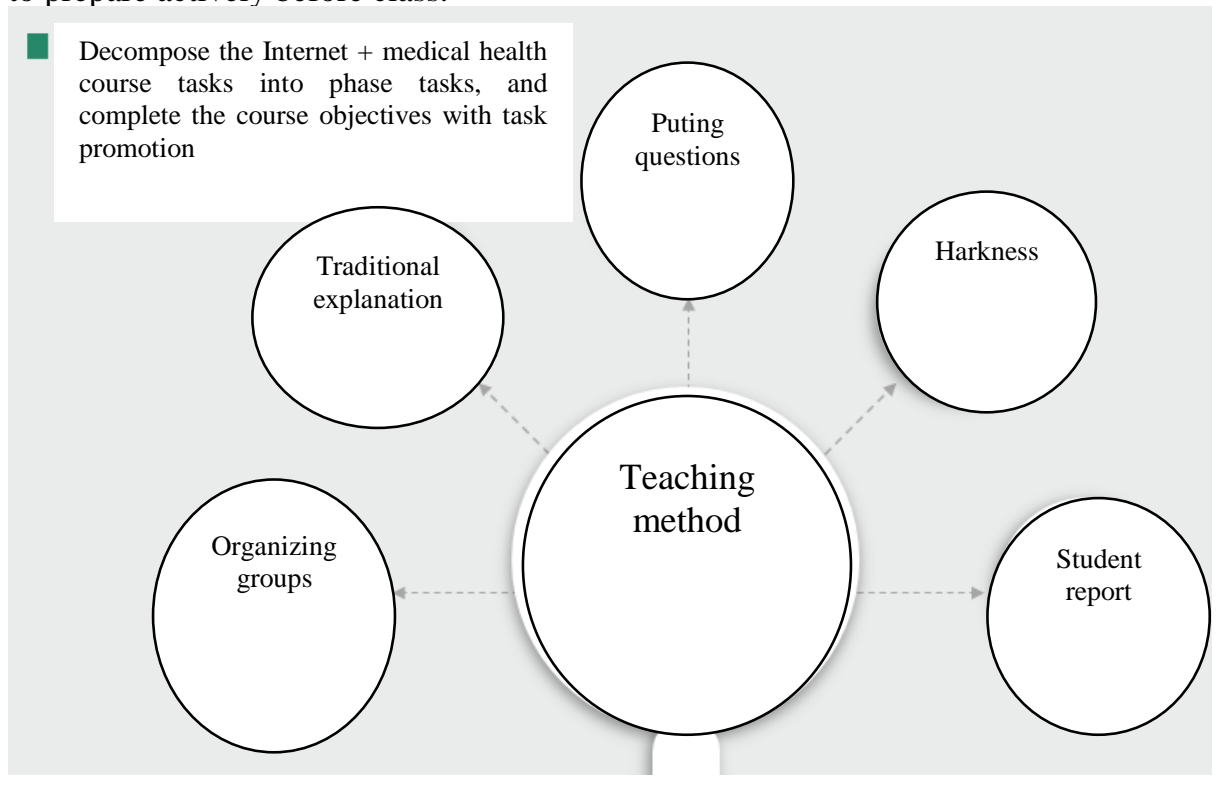

Fig. 3. Course teaching method.

\section{The TEACHING Guarantee of InTERnet Plus PubliC SERVICE COURSE BASED ON PBL}

After the design of the course problem system, it is necessary to have the following basic conditions for the smooth implementation of the course teaching:

A. Whether the preparation of persons qualified to teach is sufficient is the basis for ensuring the smooth implementation of the classroom

Open classroom is a challenge to teachers' ability to organize, coordinate and master domain knowledge and Internet technology. In order to ensure high quality classroom teaching, teachers should be well prepared in advance. The preparatory work includes the following:

a. Advance layout of the overall teaching content framework of the course.

b. Connect each class and leave plenty of preparation time for students to ensure that each class can be completed smoothly.

c. Estimate viewpoints of students in each topic discussion and prepare enough opinion materials.

B. Whether students can participate actively is the key to guarantee the quality of classroom teaching.
In PBL teaching, students are the main body and the leader of the class. Students must actively participate in the classroom. To motivate students, the following measures can be taken:

a. Flexibly use a variety of teaching methods to enhance students' interest in the content of the course.

b. Guiding students to study hot medical and health events with the data analysis tools they have mastered before, reflecting the sense of achievement and promoting active participation of students.

c. In the course assessment, try to increase the proportion of scores in the class discussion session, so that students pay more attention to it. For example, $40 \%$ of the usual classrooms, including participation enthusiasm, report quality, adequate preparation for literature and so on. $60 \%$ of the final essay, the title of the essay is from the usual classroom discussion issues.

C. The depth of communication between teaching and learning is a prerequisite for guaranteeing the quality of teaching.

In the teaching process based on PBL, teachers and students are required to cooperate closely. And ability of students is limited, in the process of problem-solving and literature-collecting, various questions may arise at any time. Guidance from teachers is required, after all, traditional 
classrooms have limited time, so it is necessary to make full use of the after-class time. Teachers can make full use of Internet communication methods such as WeChat Group and QQ Group to strengthen contact with students, continue the classroom to after-class, and solve any problems in the teaching process in a timely manner.

\section{CONCLUSION}

The teaching of Internet + Public Service course based on PBL can effectively improve ability of students to explore and solve problems independently. The flexible course practice mode can cultivate collaboration and communication ability of students. The active participation of students is the most basic guarantee for the quality of classroom teaching. All the links of problem design, problem solving and problem discussion are to enhance the initiative of students.

\section{REFERENCES}

[1] Liu Yang, Common Problems and Solutions in PBL Teaching Mode [J], Basic Medical Education, 2015.08

[2] Cui Bingquan, He Zhenyu, Research and Evaluation of PBL Teaching Method [J], China Higher Medical Education, 2009 (07)

[3] Chen Peiqing, Han Qiuqin, Development and Application Status of PBL Teaching Model [J], Education and Teaching Forum, 2018 (08)

[4] Liu Wenhong, Chu Lisheng, Comparative Analysis of Group Cooperative Learning and PBL Teaching Mode [J], Science and Technology Innovation Report, 2017 (31) 